\title{
Ganaya:
}

\section{Kebijakan Model Crime Prevention Through Social Development Dalam Penanggulangan Tindak Pidana Terorisme}

\author{
Dwi Nurahman, Dina Haryati Sukardi \\ Fakultas Hukum Universitas Mitra Indonesia \\ dwinurahman@umitra.ac.id, dinaharyati@umitra.ac.id
}

\begin{tabular}{l}
\hline Keywords: \\
\hline Policy, Model, \\
Crime Prevention \\
Through Social \\
Development \\
(CPTSD) \\
\hline
\end{tabular}

Kata Kunci:

Kebijakan, Model, Crime Prevention Through Social Development (CPTSD)

\begin{abstract}
The problem in this study is how the implementation of the conception of Crime Prevention Through Social Development (CPTSD) by Bhabinkamtibmas in combating criminal acts of terrorism and why there are obstacles to the implementation of the conception of CPTSD by Bhabinkamtibmas in combating criminal acts of terrorism. The research method specifically uses this type of qualitative research with a normative juridical approach to the problem and an empirical approach. The types of data used are primary data and secondary data. Primary data were obtained from interviews with resource persons and secondary data from literature studies. The results of the study indicate that the CPTSD model policy by Bhabinkamtibmas in overcoming criminal acts of terrorism is carried out through preventive, preemptive, and repressive efforts. Preventive efforts are supervision of chemicals that can be processed into explosives. Preemptive efforts are holding tabligh akbar and reinstilling Pancasila values in society. The repressive effort is the establishment of the Anti-Terror Task Force. The obstacle in implementing the CPTSD model policy by Bhabinkamtibmas in overcoming criminal acts of terrorism is that Bhabinkamtibmas still lacks resources both in terms of quantity of members and in the field of facilities and infrastructure which includes the number of vehicles and task tools used to carry out Anjau Glare and binluh to the community. The Binmas Pioneer program through the CPTSD by Bhabinkamtibmas has not yet reached the target, so it has not been maximal in raising public awareness and preventing crime.
\end{abstract}

Abstrak
Problematika hukum terkait penanggulangan tindak pidana
terorisme khususnya di wilayah hukum Polres Lampung Selatan
masih menjadi salah program pokok penegakan hukum oleh
Polda Lampung. Hal ini mengingat bahwa isu perkembangan
kejahatan terorisme global telah menunjukkan berbagai
perubahan baik modus, kuantitas maupun kualitasnya. Polri
sebagai garda depan dalam menyikapi situasi tersebut
memformulasikan kebijakan model Crime Prevention Through


Social Development. Sejumlah peristiwa terorisme menunjukan adanya mata rantai antara kelompok dalam dan luar negeri. Terungkap fakta adanya keterkaitan jaringan militan lokal dengan jaringan internasional. Berdasarkan pada data survey di Polda Lampung, sejak tahun 2018 samapi saat ini Tim Gabungan Aparat Kepolisian dari Densus 88 Anti Teror Mabes Polri dan Kepolisian Daerah Lampung telah menangkap lebih kurang 20 orang yang diduga tergabung ke dalam jaringan teroris yang tersebar di beberapa kabupaten di Provinsi Lampung. Isu pokok masalah dalam penelitian ini yakni: bagaimanakah kebijakan model Crime Prevention Through Social Development oleh Bhabinkamtibmas dalam penanggulangan tindak pidana terorisme dan apa saja kendala dalam kebijakan model tersebut. Metode Penelitian secara spesifik menggunakan jenis penelitian kualitatif dengan pendekatan masalah yang digunakan secara yuridis normatif dan pendekatan empiris. Jenis data yang digunakan adalah data primer dan data sekunder. Data primer diperoleh dari wawancara dengan narasumber dan data sekunder bersumber dari studi pustaka. Berdasarkan hasil penelitian menunjukkan bahwa kebijakan model Crime Prevention Through Social Development oleh Bhabinkamtibmas dalam penanggulangan tindak pidana terorisme dilaksanakan melalui upaya preventif, preemtif, dan represif. Upaya preventif yaitu pengawasan terhadap bahan-bahan kimia yang dapat diolah menjadi bahan peledak. Upaya preemtif yaitu mengadakan tabligh akbar dan menanamkan kembali nilai-nilai Pancasila di masyarakat. Upaya represif yaitu pembentukan Satgas Anti Teror. Hambatan dalam implementasi kebijakan model Crime Prevention Through Social Development oleh Bhabinkamtibmas antara lain: Bhabinkamtibmas masih kekurangan sumberdaya baik secara kuantitas anggota, keterbatasan sarana dan prasarana yang meliputi jumlah unit kendaraan dan alat tugas, Binmas Pioneer melalui Crime Prevention Through Social Development belum mencapai sasaran, sehingga belum maksimal dalam menyadarkan masyarakat dan mencegah terjadinya paham radikalisme dan terorisme.

\section{Pendahuluan}

Terorisme merupakan kejahatan terhadap kemanusian dan tantangan untuk peradapan manusia. Terorisme tidak hanya menjadi ancaman domestik suatu negara, akan tetapi juga merupakan ancaman global setiap bangsa (Zaidan Ali, 2005). Secara semantik leksikal teror berarti kekacauan, tindak kesewenang-wenangan untuk menimbulkan kekacauan dalam masyarakat, tindak kejam dan mengancam (Polri, Baharkam, 2006). Istilah "terroris" (pelaku) dan terorisme (aksi) berasal dari kata latin "terrere" yang kurang lebih berarti membuat gemetar atau menggetarkan (Hery Firmansyah, 2011) 
Berdasarkan ketentuan yang ada dalam Pasal 1 Undang-Undang Nomor 5 Tahun 2018 tentang Perubahan atas Undang-Undang Nomor 15 Tahun 2003 tentang Penetapan Peraturan Pemerintah Pengganti Undang-Undang Nomor 1 Tahun 2002 tentang Pemberantasan Tindak Pidana Terorisme menjadi Undang-Undang, yang dimaksud.

Problematika hukum terkait penanggulangan tindak pidana terorisme khususnya di wilayah hukum Polres Lampung Selatan masih menjadi salah program pokok penegakan hukum oleh Polda Lampung. Hal ini mengingat bahwa isu perkembangan kejahatan terorisme global telah menunjukkan berbagai perubahan baik modus, kuantitas maupun kualitasnya. Polri sebagai garda depan dalam menyikapi situasi tersebut memformulasikan kebijakan model Crime Prevention Through Social Development. Sejumlah peristiwa terorisme menunjukan adanya mata rantai antara kelompok dalam dan luar negeri. Terungkap fakta adanya keterkaitan jaringan militan lokal dengan jaringan internasional. Berdasarkan pada data survey di Polda Lampung, sejak tahun 2018 samapi saat ini Tim Gabungan Aparat Kepolisian dari Densus 88 Anti Teror Mabes Polri dan Kepolisian Daerah Lampung telah menangkap lebih kurang 20 orang yang diduga tergabung ke dalam jaringan teroris yang tersebar di beberapa Kabupaten di Provinsi Lampung.

Polri yang merupakan ujung tombak dalam menangani kasus-kasus tindak pidana di Indonesia, khususnya Tindak Pidana Terorisme sebagaimana yang menjadi fokus dalam tulisan ini, diwajibkan dapat selalu siap siaga untuk berperan maksimal. Sehingga ancaman terorisme di Indonesia, khususnya di wilayah hukum Polres Lampung Selatan, dapat ditanggulangi dengan cepat dan tepat. Selain menitikberatkan pada peran Polri, khususnya Bhayangkara Pembina Keamanan Dan Ketertiban Masyarakat (Bhabinkamtibmas) di masing-masing desa/kelurahan, untuk mencegah menyebarnya ideologi teror dan mencegah seseorang bergabung dengan kelompok teroris, maka peran masyarakat pun sangatlah signifikan. Salah satu cara yang dapat dilakukan adalah dengan melakukan pemberdayaan masyarakat melalui pembangunan sosial atau Crime Prevention Through Social Development.

Konsepsi Crime Prevention Through Social Development (selanjutnya disebut CPTSD) oleh Bhayangkara Pembina Keamanan Dan Ketertiban Masyarakat (Bhabinkamtibmas) sebagai amanat dari Peraturan Kepala Kepolisian Republik Indonesia Nomor 3 Tahun 2015 tentang Pemolisian Masyarakat, ada pun output dari Crime Prevention Through Social Development di Polres Lampung Selatan adalah program Binmas Pioneer yang membentuk Sentra Komunikasi Mitra Polri (Senkom Mitra Polri) / 
Bantuan Polisi (Banpol). Orientasi CPTSD dalam penanggulangan tindak pidana terorisme dilaksanakan melalui upaya preventif, preemtif, dan represif. Adapun melalui langkah preventif meliputi peningkatan pengamanan dan pengawasan terhadap kegiatan terorisme, pengawasan terhadap bahan-bahan kimia yang dapat diolah menjadi bahan peledak, serta pengawasan kegiatan masyarakat yang mengarah pada aksi teror.

Upaya preemtif dari program Binmas Pioner melalui Senkom Mitra Polri / Bantuan Polisi diantaranya mengadakan acara guna memberikan pencerahan ajaran agama oleh tokoh-tokoh keagamaan/tabligh akbar dan menanamkan kembali pemahaman nilai-nilai pancasila di masyarakat. Upaya represif adalah dengan melaksanakan koordinasi antara lembaga / institusi terkait serta pembentukan satuan khusus sebagai langkah pemberantasan tindak pidana terorisme (Satgas Anti Teror). Pelaksanaan penanggulangan tindak pidana terorisme masih menuai berbagai hambatan sehingga belum secara maksimal memberikan kesadaran terhadap masyarakat dalam pencegahan dan penanggulangan tindak kriminalitas seperti terorisme. Konsepsi Crime Prevention Through Social Development dalam kegiatan Bhabinkamtibmas (penerapan polmas/Binmas Pioneer) sebagai terobosan penanggulangan tindak pidana terorisme.

\section{Metode}

Metode Penelitian secara spesifik menggunakan jenis penelitian kualitatif dengan pendekatan masalah secara yuridis normatif dan pendekatan empiris. Jenis data yang digunakan adalah data primer dan data sekunder. Data primer diperoleh dari wawancara dengan narasumber dan data sekunder bersumber dari studi pustaka. Narasumber penelitian yakni: Binmas Polres Lampung Selatan, Bhabinkamtibmas, Akademisi, Forum Koordinasi Pencegahan Terorisme (FKPT) Provinsi Lampung, dan Tokoh Mayarakat.

Data yang diperoleh dianalisis secara kualitatif yang artinya hasil penelitian ini dideskripsikan dalam bentuk penjelasan dan uraian kalimat-kalimat yang mudah dibaca dan dimengerti untuk diinterpretasikan dan ditarik kesimpulan mengenai Crime Prevention Through Social Development oleh Bhayangkara Pembina Keamanan dan Ketertiban Masyarakat (Bhabinkamtibmas) dalam penanggulangan tindak pidana terorisme, sehingga dapat diperoleh gambaran yang jelas tentang masalah yang diteliti. Dari hasil analisis tersebut dapat dilanjutkan dengan menarik kesimpulan secara induktif, yaitu cara berfikir dalam mengambil kesimpulan secara umum yang didasarkan atas fakta-fakta yang bersifat khusus, dan selanjutnya dari berbagai kesimpulan tersebut diajukan saran/rekomendasi penelitian (Sogiono, 2011). 


\section{Hasil dan Pembahasan}

Berdasarkan pada data survey di Polda Lampung, sejak tahun 2018 sampai saat ini Tim Gabungan Aparat Kepolisian dari Densus 88 Anti Teror Mabes Polri dan Kepolisian Daerah Lampung telah menangkap lebih kurang 20 orang yang diduga tergabung ke dalam jaringan teroris yang tersebar di beberapa kabupaten di Provinsi Lampung. Berdasarkan data Polda Lampung bahwa rangkaian peristiwa pemboman dan aksi-aksi teroris yang terjadi khususnya di wilayah hukum Polda Lampung telah mengakibatkan ketakutan bagi warga masyarakat. Adapun serangakain peristiwapristiwa teror di wilayah Hukum Polda Lampung sebagai berikut:

Table 1. Data Peristiwa Pemboman Dan Aksi-Aksi Teroris Yang Terjadi Khususnya

Di Wilayah Hukum Polda Lampung

\begin{tabular}{|c|c|c|c|c|}
\hline No. & Tindak Pidana & $\begin{array}{l}\text { Temapt Kejadian } \\
\text { Perkara (TKP) }\end{array}$ & Upaya Hukum & Tahun \\
\hline 1 & $\begin{array}{l}\text { Tindak Pidana } \\
\text { Terorisme (Pasal } \\
1 \quad \text { angka } 1 \\
\text { Undang-Undang } \\
\text { Nomor } 15 \text { Tahun } \\
\text { 2003) }\end{array}$ & \begin{tabular}{lr}
\multicolumn{2}{l}{ Jalan Bung Tomo, } \\
Kelurahan Gedong \\
Air, Kecamatan \\
Tanjung $\quad$ Karang \\
Barat, & Bandar \\
Lampung
\end{tabular} & $\begin{array}{l}\text { Penangkapan dan } \\
\text { Penahanan Terduga } \\
\text { Terorisme }\end{array}$ & $\begin{array}{l}\text { tanggal } 29 \\
\text { September } \\
2017\end{array}$ \\
\hline 2 & $\begin{array}{l}\text { Tindak Pidana } \\
\text { Terorisme (Pasal } \\
1 \quad \text { angka } 1 \\
\text { Undang-Undang } \\
\text { Nomor } 15 \text { Tahun } \\
2003)\end{array}$ & $\begin{array}{l}\text { Dusun I Tirto } \\
\text { Kencono, Kampung } \\
\text { Tanggulangin, } \\
\text { Punggur, } \\
\text { Kabupaten } \\
\text { Lampung Tengah }\end{array}$ & $\begin{array}{l}\text { Penangkapan dan } \\
\text { Penahanan Terduga } \\
\text { Terorisme }\end{array}$ & $\begin{array}{lr}\text { Tangal } & 15 \\
\text { Agustus } & 2016\end{array}$ \\
\hline 3 & $\begin{array}{l}\text { Tindak Pidana } \\
\text { Terorisme (Pasal } \\
1 \quad \text { angka } 1 \\
\text { Undang-Undang } \\
\text { Nomor } 15 \text { Tahun } \\
2003)\end{array}$ & $\begin{array}{l}\text { Kecamatan } \\
\text { Panjang, Bandar } \\
\text { Lampung }\end{array}$ & $\begin{array}{l}\text { Penangkapan dan } \\
\text { Penahanan Terduga } \\
\text { Terorisme }\end{array}$ & $\begin{array}{l}2 \\
2016\end{array}$ \\
\hline
\end{tabular}

Sumber Data : Polda Lampung 2021

Serangan teror dapat terjadi kapan saja dan di mana saja. Berbagai aksi teror bom di berbagai wilayah hukum Polda Lampung tahun terakhir 2020 menunjukkan bahwa tak satu pun wilayah yang kebal terhadap aksi teror. Gerakan terorisme dinilai sebagai salah satu ancaman terbesar bagi manusia dan kemanusiaan di masa-masa mendatang, dan akan terus merebak luas jika tidak segera diberantas. Penerapan konsepsi Polmas melalui program Crime Prevention Through Social Development oleh Bhabinkamtibmas dalam penanggulangan tindak pidana terorisme dan tindak pidana umum dapat dilihat pada tabel berikut: 
Table 2. Penerapan konsepsi Polmas melalui program Crime Prevention Through Social

Development

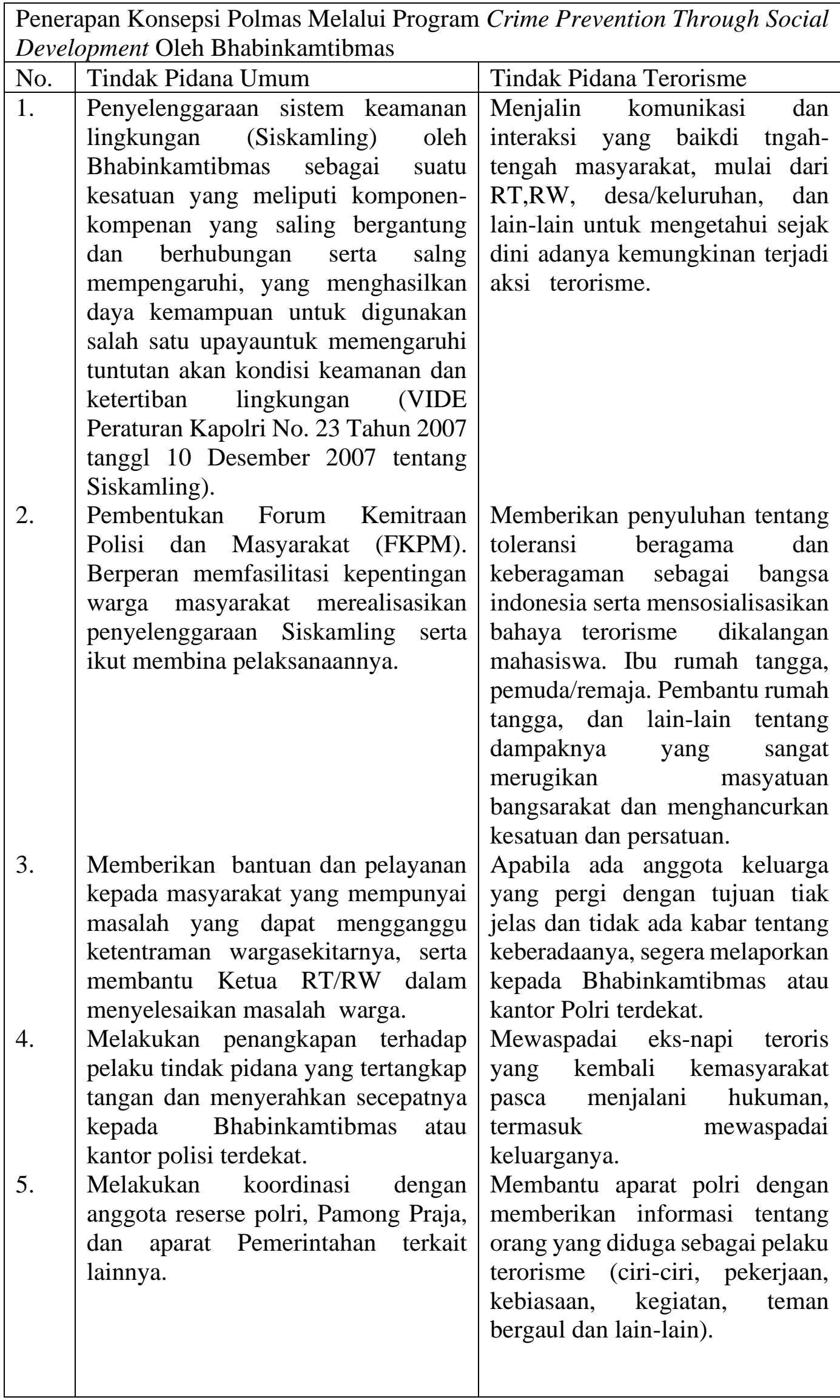




\begin{tabular}{|l|l|l|}
\hline 6. & $\begin{array}{l}\text { Memberikan peringatan-peringatan } \\
\text { untuk mencegah terjadinya kejahatan, } \\
\text { bencana alam, dan lain-lain. }\end{array}$ & $\begin{array}{l}\text { Termonitor dan terpantau } \\
\text { perorangan/ kelompok yang } \\
\text { diduga terlibat dalam jaringan } \\
\text { terorisme. }\end{array}$ \\
7. & $\begin{array}{l}\text { Mewujudkan kesadaran warga } \\
\text { penngulangan lingkungan nya dalam } \\
\text { pencegahan dan gangguan } \\
\text { Kamtibmas terhadap setiap } \\
\text { kemungkinan timbulnya kejahatan. }\end{array}$ & $\begin{array}{l}\text { agama dan masyarakat untuk } \\
\text { mencegah para pemuda untuk } \\
\text { tidak masuk dalam kelompok } \\
\text { jaringan terorisme. }\end{array}$ \\
\hline
\end{tabular}

Berdasarkan konsepsi Crime Prevention Through Social Development (CPTSD) oleh Bhayangkara Pembina Keamanan dan Ketertiban Masyarakat (Bhabinkamtibmas) di atas, bahwa sebagai amanat dari Peraturan Kepala Kepolisian Republik Indonesia Nomor 3 Tahun 2015 tentang Pemolisian Masyarakat, ada pun output dari Crime Prevention Through Social Development adalah Binmas Pioneer yang membentuk Pemolisian Masyarakat/Polisi Desa/Bantuan Polisi. Orientasi CPTSD dalam penanggulangan tindak pidana terorisme dilaksanakan melalui upaya preventif, preemtif, dan represif.

Adapun melalui langkah preventif meliputi diantaranya peningkatan pengamanan dan pengawasan terhadap kegiatan terorisme, pengawasan terhadap bahan-bahan kimia yang dapat diolah menjadi bahan peledak, serta pengawasan kegiatan masyarakat yang mengarah pada aksi teror melalui Binmas Pioneer yang membentuk Pemolisian Masyarakat/Polisi Desa/Bantuan Polisi.

Upaya preemtif oleh Binmas Pioneer melalui Pemolisian Masyarakat/Polisi Desa/Bantuan Polisi diantaranya mengadakan acara guna memberikan pencerahan ajaran agama oleh tokoh-tokoh keagamaan/tabligh akbar dan menanamkan kembali pemahaman nilai-nilai pancasila di masyarakat. Upaya represif adalah dengan melaksanakan koordinasi antara lembaga / institusi terkait serta pembentukan satuan khusus sebagai langkah pemberantasan tindak pidana terorisme (Satgas Anti Teror). Pelaksanaan konsepsi Crime Prevention Through Social Development oleh Bhayangkara Pembina Keamanan dan Ketertiban Masyarakat (Bhabinkamtibmas) dalam penanggulangan tindak pidana terorisme masih menuai berbagai hambatan sehingga kegiatan Bhayangkara Pembina Keamanan dan Ketertiban Masyarakat (Bhabinkamtibmas) (penerapan polmas) belum secara maksimal memberikan kesadaran terhadap masyarakat dalam pencegahan dan penanggulangan tindak kriminalitas terorisme. 
Binmas Pioneer melalui Pemolisian Masyarakat/Polisi Desa/Bantuan Polisi diantaranya adalah Senkom Mitra Polri yakni kelompok masyarakat yang ingin berperan dalam membantu menginformasikan dan membantu pengamanan lingkungan disekitarnya atau di mana saja berada serta memberikan informasi kepada masyarakat tentang pentingnya pengamanan swakarsa di lingkungan masing-masing sebagai wujud Bela Negara dengan semangat patriotisme dan nasionalisme dalam wadah NKRI. Senkom Mitra Polri dibentuk sebagai tindak lanjut dari pelaksanaan Undang-Undang Nomor 2 Tahun 2002. Selanjutnya pada tanggal 1 Januari 2004 di Jakarta dibentuklah Senkom Mitra Polri sebagai wadah kelompok sadar kamtibmas oleh anggota mitra kamtibmas Mabes Polri. Ditindaklanjuti dengan Surat Telegram Kapolri Nopol: ST/526/V/2007 tanggal 7 Mei 2007 tentang perintah kepada para Kapolda untuk membina Senkom untuk menjadi mitra Polri sehingga diharapkan dapat berperan serta sebagai anggota Forum Komunikasi Polisi Masyarakat (FKPM) untuk memecahkan masalah-masalah sosial yang berdampak dapat menjadi sumber gangguan kamtibmas di lingkungan komunitasnya sebagai barometer stabilitas politik, pertahanan dan keamanan.

Perkembangan kebijakan dan strategi pimpinan Polri tentang Polmas (Perpolisian masyarakat) sebagai tindak lanjut dari Skep Kapolri No. Pol. : SKEP /737X/2005. Program ini ditujukan untuk mendekatkan polisi dengan masyarakat agar masyarakat terdorong/termotivasi bekerjasama dengan kepolisian dalam membantu tugas pokok kepolisian untuk menciptakan kamtibmas (keamanan dan ketertiban masyarakat). Sejalan dengan program Polmas, Senkom Mitra Polri adalah wujud dari program multiguna sebagai masyarakat sadar kamtibmas bertujuan untuk meningkatkan kesadaran hukum dan kamtibmas serta mewujudkan partisipasi akan pentingnya arti sinergi antara masyarakat dan aparat. Adapun output kegiatan Binmas Pioneer melalui Pemolisian Masyarakat/Polisi Desa/Bantuan Polisi/Senkom Mitra Polri:

a. Pemantauan : melakukan pemantauan cuaca, lalu lintas, laporan situasi Kamtibmas, informasi yang menonjol atau informasi yang penting melalui radio pemancar ulang.

b. Kerja sama dengan lembaga atau instansi : melakukan kerja sama pelatihan dan sosialisasi yang disediakan lembaga atau instansi untuk meningkatkan kualitas sumber daya manusia (SDM) dalam rangka menumbuhkan motivasi keamanan mandiri serta memacu terciptanya kamtibmas. Kegiatan sosial masyarakat : antara lain melakukan pelayanan secara langsung dalam penanganan bencana dan kecelakaan, pengamanan pertunjukan dan demonstrasi, serta bantuan komunikasi dan informasi. 
Hambatan dalam penerapan konsepsi Polmas melalui program Crime Prevention Through Social Development oleh Bhayangkara Pembina Keamanan dan Ketertiban Masyarakat (Bhabinkamtibmas) dalam penanggulangan tindak pidana terorisme yakni masyarakat merasa takut untuk menyampaikan informasi-informasi yang diketahuinya, terlebih berkaitan dengan tindak pidana terorisme. Ada masyarakat yang memang tertutup untuk melaksanakan interaksi, baik kepada polisi maupun tetangga sekitarnya, biasanya perilaku yang demikian merupakan perilaku yang merujuk pada perilaku terduga teroris.

Beberapa hal yang menjadi kendala dalam menerapkan konsep CPTSD adalah :

1) Adanya beberapa oknum masyarakat yang tertutup, tidak mau diajak interaksi baik dari Bhayangkara Pembina Keamanan dan Ketertiban Masyarakat (Bhabinkamtibmas) sendiri maupun dari tetangga sekitar

2) Kurangnya personel Bhabinkamtibmas itu sendiri, yang mana untuk saat ini 1 Bhabinkamtibmas : 1000 penduduk.

3) Kurangnya sosialisasi secara langsung oleh Bhabinkamtibmas kepada masyarakat, yang selama ini terbatas hanya dari Bhabinkamtibmas ke pamong desa setempat

4) Adanya kultur dari masyarakat Desa Karang Anyar itu sendiri yang agak susah dalam menerima masukan yang positif.

Selanjutnya hambatan dalam penerapan konsepsi Polmas melalui program Crime Prevention Through Social Development oleh Bhayangkara Pembina Keamanan dan Ketertiban Masyarakat (Bhabinkamtibmas) dalam penanggulangan tindak pidana terorisme menunjukkan bahwa kinerja dalam penerapan konsepsi Polmas melalui program Crime Prevention Through Social Development oleh Bhayangkara Pembina Keamanan dan Ketertiban Masyarakat (Bhabinkamtibmas) dalam penanggulangan tindak pidana terorisme dirasa belum efektif. Hal ini ditunjukkan oleh beberapa faktor sebagai berikut:

a. Bhayangkara Pembina Keamanan dan Ketertiban Masyarakat (Bhabinkamtibmas) masih kekurangan sumberdaya dibeberapa bidangnya terutama di bidang sumber daya manusia itu sendiri, sarana dan prasarana seperti jumlah unit kendaraan, alat tugas untuk mobilisasi anggota dan minimnya kapasitas ruangan pada Unit binmas polsek.

b. Program Polmas melalui Crime Prevention Through Social Development oleh Bhayangkara Pembina Keamanan dan Ketertiban Masyarakat (Bhabinkamtibmas) dalam penanggulangan tindak pidana terorisme belum mencapai sasaran. 
c. Bhayangkara Pembina Keamanan dan Ketertiban Masyarakat (Bhabinkamtibmas) secara keseluruhan belum maksimal dimana secara persuasif melalui kegiatan Bhayangkara Pembina Keamanan dan Ketertiban Masyarakat (Bhabinkamtibmas) belum secara luas memberikan kesadaran terhadap masyarakat akan penerapan polmas dan pencegahan tindak kriminalitas. Selanjutnya dalam hal bina kusuma krakatau masih belum memberikan outcome yang baik.

d. Kurangnya sarana dan Prasarana yang dimiliki oleh Bhayangkara Pembina Keamanan dan Ketertiban Masyarakat (Bhabinkamtibmas) sehingga menghambat dalam penerapan konsepsi Polmas melalui program Crime Prevention Through Social Development dalam penanggulangan tindak pidana terorisme, maka perlu adanya penambahan sarana dan prasarana untuk menunjang Bhayangkara Pembina Keamanan dan Ketertiban Masyarakat (Bhabinkamtibmas) dalam menjalankan tugas.

e. Bhayangkara Pembina Keamanan dan Ketertiban Masyarakat (Bhabinkamtibmas) sebaikanya menambah intensitas dalam menjalankan kegiatan dan program Crime Prevention Through Social Development dalam penanggulangan tindak pidana terorisme kepada masyarakat khususnya kegiatan Anjau silau dan Binluh.

\section{Kesimpulan}

Berdasarkan uraian di atas, peneliti menganalisis bahwa kebijakan model Crime Prevention Through Social Development oleh Bhayangkara Pembina Keamanan dan Ketertiban Masyarakat (Bhabinkamtibmas) dalam penanggulangan tindak pidana terorisme dilaksanakan melalui upaya preventif, preemtif, dan represif. Adapun melalui langkah preventif meliputi diantaranya peningkatan pengamanan dan pengawasan terhadap kegiatan terorisme, pengawasan terhadap bahan-bahan kimia yang dapat diolah menjadi bahan peledak serta pengawasan kegiatan masyarakat yang mengarah pada aksi teror. Adapun melalui upaya preemtif diantaranya mengadakan acara guna memberikan pencerahan ajaran agama oleh tokoh-tokoh kharismatik di bidang keagamaan / tabligh akbar dan menanamkan kembali pemahaman nilai-nilai pancasila di masyarakat. Adapun melalui upaya represif adalah dengan melaksanakan koordinasi antara lembaga / institusi terkait (Polri, BNPT, FKPT, Tokoh Masyarakat, Tokoh Agama) serta pembentukan satuan tugas khusus sebagai langkah pemberantasan tindak pidana terorisme (Satgas Anti Teror). Hambatan pada implementasi kebijakan model Crime Prevention Through Social Development oleh Bhayangkara Pembina Keamanan dan Ketertiban Masyarakat (Bhabinkamtibmas) dalam penanggulangan tindak pidana terorisme itu sendiri antara lain 
masih kurangnya sumber daya dibeberapa bidang terutama di jumlah sumber daya manusia, bidang sarana dan prasarana seperti jumlah unit kendaraan, alat tugas untuk mobilisasi anggota dan minimnya kapasitas ruangan pada Unit binmas polsek. Program Binmas Pioneer melalui Crime Prevention Through Social Development oleh Bhayangkara Pembina Keamanan dan Ketertiban Masyarakat (Bhabinkamtibmas) dalam penanggulangan kriminalitas khususnya tindak pidana terorisme belum tepat mencapai sasaran. Sehingga, kegiatan Binmas Pioneer (penerapan polmas) belum secara maksimal dapat memberikan kesadaran terhadap masyarakat dan pencegahan tindak kriminalitas.

\section{Daftar Pustaka}

Ali Syafa'at, Muchammad, (2005), Tindak Pidana Teror, Belenggu Baru Bagi Kebebasan, Imparsial, Jakarta.

Firmansyah, Hery. (2011). Mimbar Hukum Vol. 23 No. 2 : Upaya Penanggulangan Tindak Pidana Terorisme di Indonesia.

Sogiono, (2011), Metode Penelitian Administrasi, Alfabeta, Bandung.

Salam, Moch Faisal, (2003), Motivasi Tindakan Terorisme, Mandar Maju, Jakarta.

Zaidan Ali, M. 2005. Jurnal Yuridis Vol. 2 No. 4 : Penanggulangan Tindak Pidana Terorisme (Perspektif Sosiologis).

Polri, Baharkam. (2006). Buku Pintar Bhabinkamtibmas : Edisi Ketiga, Ditbinmas Baharkam Polri, Jakarta.

Undang-Undang Nomor 5 Tahun 2018 tentang Perubahan atas Undang-Undang Nomor

15 Tahun 2003 tentang Penetapan Peraturan Pemerintah Pengganti UndangUndang Nomor 1 Tahun 2002 tentang Pemberantasan Tindak Pidana Terorisme.

Peraturan Kepala Kepolisian Republik Indonesia Nomor 3 Tahun 2015 tentang Pemolisian Masyarakat. 